\title{
Autoimmunity to Collagen in Adjuvant Arthritis of Rats
}

\author{
David E. Trentham, W. Joseph McCune, Pia Susman, and \\ JoHN R. DAvid, Departments of Medicine, Harvard Medical School, \\ and Robert B. Brigham Division of the Affiliated Hospitals Center, Inc., \\ Boston, Massachusetts 0211.5
}

A B S T R A C T Arthritis can be induced in rats by intradermal injection of oil containing bacterial derivatives (adjuvant-induced arthritis) or cartilage collagen (type II collagen-induced arthritis). It was of interest, therefore, to determine whether collagen functions as an autoantigen in rats with adjuvant arthritis. Blood mononuclear cells from the majority of rats with adjuvant arthritis exhibited enhanced thymidine incorporation to homologous types I and II collagens, as well as to purified protein derivative of tuberculin. In contrast, cells from rats remaining nonarthritic after injection of adjuvant did not respond to collagen, although they did react to tuberculin. Similar results were obtained with a radiometric ear assay used to quantify intradermal delayed-type hypersensitivity in vivo. Using passive hemagglutination, autoantibodies to these collagens and their denatured $\alpha$-chains were frequently detected in the sera of rats late in the course of adjuvant arthritis. Rats with inflammation of a hindlimb induced by turpentine did not acquire sensitivity to collagen. These data indicate that autoimmunity to collagen is a common feature of adjuvant- and collagen-induced arthritis, both of which are considered to be mediated by immunologic mechanisms.

\section{INTRODUCTION}

Adjuvant disease of rats is an experimental polyarthritis induced by intradermal injection of an oily vehicle containing bacterial components, i.e., complete Freund's adjuvant (1-16). Adjuvant arthritis can be passively transferred by lymphoid cells $(17-19)$, implicating immunologic mechanisms in its pathogenesis. Recently, an arthritis morphologically similar to classical adjuvant disease has been induced in rats by injection of oil containing an apparently nonim-

\footnotetext{
A preliminary account of part of this work was presented at the 34th Annual Meeting of the American Federation for Clinical Research, April 30-May 2, 1977, Washington, D. C., and was published in 1977. Clin. Res. 25: 369. (Abstr.)

Received for publication 26 October 1979 and in revised form 14 July 1980.
}

munogenic alkyldiamine, $N, N$-dioctadecyl- $N^{\prime}, N$-bis(2-hydroxyethyl)propanediamine (CP-20961) (20). Like complete Freund's adjuvant, a dispersion or solution of this synthetic compound in oil possesses potent adjuvant properties for humoral and cellmediated processes in rats $(20)$. This recognition has furnished additional support for earlier suggestions (8, 21-25) that the immunogen(s) responsible for the induction of adjuvant arthritis is endogenous, perhaps a constituent of normal host tissue (20).

Intradermal injection of oil containing type II collagen derived from cartilage (26-31) or the vitreous of the eye (32) can also produce a polyarthritis in rats. Since the clinical $(26,31,32)$ and histologic $(26$, $28,31)$ features of type II collagen-induced arthritis are similar to those of adjuvant arthritis, it was of interest to determine whether collagen functions as an autoantigen in adjuvant arthritis. In this paper, we report that rats with adjuvant arthritis can exhibit cellular and humoral sensitivities to homologous type I and type II collagens. These data are consistent with the possibility that autoimmune responses to collagen participate in the pathogenesis of adjuvantinduced as well as collagen-induced arthritis in rats.

\section{METHODS}

Rats. We used outbred female Wistar rats weighing $175-225 \mathrm{~g}$ or weanling rats of the same strain (Charles River Laboratories, Wilmington, Mass.).

Collagens. Native type I and type II collagens were purified by neutral salt extraction from the tail tendons and xiphoid cartilages, respectively, of weanling rats rendered lathyritic by the administration of $\beta$-aminopropionitrile fumarate (Sigma Chemical Co., St. Louis, Mo.) (26). Differential salt precipitation removed type I collagen from our cartilage collagen preparation (33). Results from a uronic acid assay, carboxymethyl-cellulose chromatography and amino acid analysis confirmed the purity of each preparation (26). Because endotoxin may be mitogenic for rat lymphocytes (34), we analyzed our collagens for endotoxin with a Limulus amebocyte lysate test kit (Microbiological Associates, Walkersville, Md.). No endotoxin was detected. We also prepared the denatured constituent $\alpha 1$ (I) and $\alpha 2$ chains of rat type I collagen and the $\alpha$ l (II) chains comprising rat type II collagen by carboxymethyl-cellulose chromatography (26). 
Reference antisera. We obtained reference antisera to native homologous type II collagen by bleeding rats that had been injected intradermally $21 \mathrm{~d}$ earlier with $0.5 \mathrm{mg}$ of type II collagen dissolved in $0.5 \mathrm{ml}$ of $0.1 \mathrm{M}$ acetic acid at $4^{\circ} \mathrm{C}$ for $24 \mathrm{~h}$ and emulsified in $0.5 \mathrm{ml}$ cold incomplete Freund's adjuvant (Difco Laboratories, Detroit, Mich.) (26). Using an otherwise identical protocol, antibodies to rat type I collagen and $\alpha$-chains could be produced only by use of complete Freund's adjuvant (27). For these injections, we used complete Freund's adjuvant containing Mycobacteria butyricum (Difco Laboratories, code 0638), because intradermal injection of $0.5 \mathrm{ml}$ of this type of adjuvant does not induce arthritis in this strain of rats (26).

Induction of arthritis. Adjuvant arthritis was produced by injecting rats intradermally with $0.1 \mathrm{ml}$ CFA H37Ra. ${ }^{1}$ This adjuvant was made to contain desiccated, heat-killed Mycobacteria tuberculosis strain H37Ra (Difco Laboratories, code 3114), which had been finely ground with a tissue pulverizer and added to incomplete Freund's adjuvant at a concentration of $10 \mathrm{mg} / \mathrm{ml}$ oil (26). Collagen arthritis was induced by the procedure used to obtain reference antisera to type II collagen. The injection sites were on the back in both protocols.

Production of a nonspecific hindlimb inflammation. As a control for the adjuvant- and collagen-induced arthritis, we incited periarticular inflammation in age-matched rats by injecting the volar pad of the right hindpaw with $0.3 \mathrm{ml}$ turpentine oil (Fisher Scientific Co., Pittsburgh, Pa.) $(35,36)$ at weekly intervals. We injected only one paw, because adjuvant- or collagen-induced arthritis frequently involved a single hindlimb and because of the considerable inflammation created by this regimen. After $3 \mathrm{wk}$, these rats were studied to determine whether they had become sensitized to collagen.

Evaluation of arthritis. The severity of adjuvant-, collagen-, and turpentine-induced arthritis was quantified by an arthritic index $(26,28,37)$. In brief, each paw was graded from 0 to 4 based on the degree of periarticular erythema and swelling (26). A summated index was then derived for each rat. Light microscopic and radiographic evaluations (26) of adjuvant arthritis and the turpentine-induced hindlimb inflammation were also performed in selected rats.

Thymidine-incorporation assay. Cellular sensitivities to collagen, as well as to the mycobacteria present in CFA H37Ra, were quantified in vitro by antigen-induced tritiated thymidine $\left(\left[{ }^{3} \mathrm{H}\right] \mathrm{TdR}\right)$ incorporation responses by blood mononuclear cells. Blood was obtained by cardiac puncture, and mononuclear cells were isolated on gradients of FicollHypaque. $2 \times 10^{5}$ cells were then cultured in quadruplicate for $4 \mathrm{~d}$ in the presence or absence of antigens by a previously described microtechnique (27). Based on prior dose-response studies (27), assays from almost all rats included cells exposed to concentrations of 100 and $250 \mu \mathrm{g} / \mathrm{ml}$ of each collagen and $50 \mu \mathrm{g} / \mathrm{ml}$ of purified protein derivative of tuberculin (PPD, kindly supplied by the National Institute of Allergy and Infectious Diseases, Bethesda, Md., through the Joint United States-Japan Tuberculosis Program). Concentrations employed for cultures with $\alpha$-chains were identical to those used for native collagens. As controls, assays for each rat also included cells cultured with the mitogens phytohemagglutinin-M (Difco Laboratories) and concanavalin A (Miles Laboratories, Inc., Elkhart, Ind.) (27). Incorporation of $\left[{ }^{3} \mathrm{H}\right]-$ $\mathrm{TdR}$ by cells was expressed as mean counts per minute $\pm \mathrm{SE}$

\footnotetext{
${ }^{1}$ Abbreviations used in this paper: CFA H37Ra, complete Freund's adjuvant containing $M$. tuberculosis strain H37Ra; $\left[{ }^{3} \mathrm{H}\right] \mathrm{TdR}$, tritiated thymidine; PPD, purified protein derivative of tuberculin; REI, radiometric ear index; SI, stimulation index.
}

of the mean for the quadruplicate cultures. A stimulation index (SI) was then derived where $\mathrm{SI}=$ (mean counts per minute $\left[{ }^{3} \mathrm{H}\right] \mathrm{TdR}$ incorporated by cultures stimulated with collagen, PPD, or mitogen $) /\left(\right.$ mean counts per minute $\left[{ }^{3} \mathrm{H}\right]-$ $\mathrm{TdR}$ incorporated in unstimulated cultures). SI in this paper represent the maximal response induced by either of the two doses of collagen (38) or the single dose of PPD or mitogen.

To derive values that represent statistically significant proliferation, cells from 23 immunologically naive rats were cultured with types I and II collagens, as well as PPD. The SI from these assays were used to determine the random distribution. SI that exceed the mean $+3 \mathrm{SD}$ of these control values are considered significant proliferation in this paper. By these criteria, $S I \geq 2$ were clearly significant responses to collagen or PPD.

Radiometric ear assay. Intradermal delayed-type hypersensitivity to collagen or PPD was quantified in vivo by a radiometric ear assay (39-41). Our assay (30) was modified from one previously described by Kostiala (41). In brief, type I or type II collagen was dissolved at a concentration of $1.0 \mathrm{mg} / \mathrm{ml}$ in $0.1 \mathrm{M}$ acetic acid at $4^{\circ} \mathrm{C}$ for $24 \mathrm{~h}$ and then dialyzed overnight against cold $0.05 \mathrm{M}$ calcium acetate. PPD was dissolved at an identical concentration in $0.9 \%$ sodium chloride. To radiolabel dividing cells that might accumulate at the site of a delayed reaction (39-41), a rat was injected subcutaneously with $\left[{ }^{3} \mathrm{H}\right] \mathrm{TdR}$ (specific activity $6.7 \mathrm{Ci} / \mathrm{mmol}$, New England Nuclear, Boston, Mass.) at a dose of $0.34 \mu \mathrm{Ci} / \mathrm{g}$ body wt. $24 \mathrm{~h}$ later, $20 \mu \mathrm{l}$ of the collagen or PPD solution was injected intradermally into the right ear. To control for any inflammation attributable to the buffer, an identical volume of calcium acetate or sodium chloride solution alone was injected into the left ear. After $24 \mathrm{~h}$ (39-41), we sacrificed the rat and obtained punch biopsies $6 \mathrm{~mm}$ in diameter from both ears. This assay does not detect a humoral response at this time (41). After digestion of the tissue (41), the radioactivity present in each biopsy was counted, and the radiometric ear index (REI) was expressed as the ratio of the counts per minute in the antigen-challenged ear vs. the control ear (41). As in our $\left[{ }^{3} \mathrm{H}\right] \mathrm{TdR}$ incorporation assays, REI derived from 10 naive rats tested with type I collagen, type II collagen, and PPD determined random distributions. REI exceeding the mean +3 SD of the control values for each antigen are considered significant responses. By these criteria, REI $\geq 1.6$ indicate cellular sensitization to any of these antigens.

Hemagglutination assay. Blood was collected from rats by cardiac puncture or distal tail amputation (27), and sera were stored at $-70^{\circ} \mathrm{C}$. Antibodies to native collagens and $\alpha$-chains were quantified by passive microhemagglutination using human (blood group $\mathbf{O}, \mathbf{R h}+$ ) erythrocytes fixed by glutaraldehyde and coated with collagen (27). Titers are expressed as serial- $\log _{2}$ dilutions. Antibody specificities were assessed in reference antisera by passive hemagglutination techniques (42).

Statistical analysis. Comparisons of mean group data were performed by use of Student's $t$ test.

\section{RESULTS}

Clinical features of adjuvant arthritis. 148 of 328 rats $(45 \%)$ injected with CFA H37Ra experienced an explosive onset of arthritis 11-17 d after injection (mean \pm SEM 13.2 \pm 0.3 ). The remaining rats showed no macroscopic evidence of arthritis during observation periods of up to $6 \mathrm{wk}$ after injection. Histologic and radiographic evaluation of the hindlimbs of 20 rats clinically adjudged to be nonarthritic $24 \mathrm{~d}$ after in- 
jection of CFA H37Ra showed no evidence of adjuvant disease. The arthritic index of the first 46 adjuvant arthritic rats was calculated $1 \mathrm{wk}$ after the onset of arthritis. The mean index $(6.5 \pm 0.5)$ was similar to those obtained in our previous study of adjuvant- and collagen-induced arthritis (26). As in our earlier assessment (26), we could discern no clinical differences between these two arthritides. In agreement with another study (43), clinical evidence of active joint inflammation persisted 3-4 wk. Ankles from nine rats evaluated by light microscopy 28-42 d (mean 35.0 \pm 2.3 ) after the onset of adjuvant arthritis revealed fibrous and bony ankylosis of the joint, but only a few mononuclear cells remained in the periarticular tissues.

Cellular sensitivity to native collagens in adjuvant arthritis. The majority of rats with adjuvant-induced arthritis exhibited cellular sensitivity to homologous type I and type II collagens. In $\left[{ }^{3} \mathrm{H}\right] \mathrm{T} d \mathrm{R}$ incorpora- tion assays (Fig. 1), cells from 24 and 28 of the 32 arthritic rats responded with $S I \geq 2$ to types I and II collagens, respectively. The mean SI to both collagens was significantly higher in cells from arthritic rats compared with cells from rats remaining nonarthritic after injection of CFA H37Ra (in arthritic vs. nonarthritic rats, mean $\mathrm{SI} \pm \mathrm{SEM}$ to type I collagen was $3.0 \pm 0.3$ vs. $1.2 \pm 0.2$, and mean SI to type II collagen was $3.8 \pm 0.4$ vs. $1.0 \pm 0.1, P<0.0001$ for both responses). Cells from 16 of 30 (53\%) arthritic and 13 of $27(48 \%)$ nonarthritic adjuvant-injected rats responded with SI $\geq 2$ to PPD. However, the mean SI to PPD did not differ significantly between the two groups (mean SI, $5.2 \pm 1.0$ arthritic vs. $3.0 \pm 0.7$ nonarthritic, $P$ not significant).

Delayed-type hypersensitivity to collagen was also frequently found in vivo in rats with adjuvant arthritis using the radiometric ear assay (Fig. 2) (in arthritic vs. nonarthritic rats previously injected with CFA H37Ra,

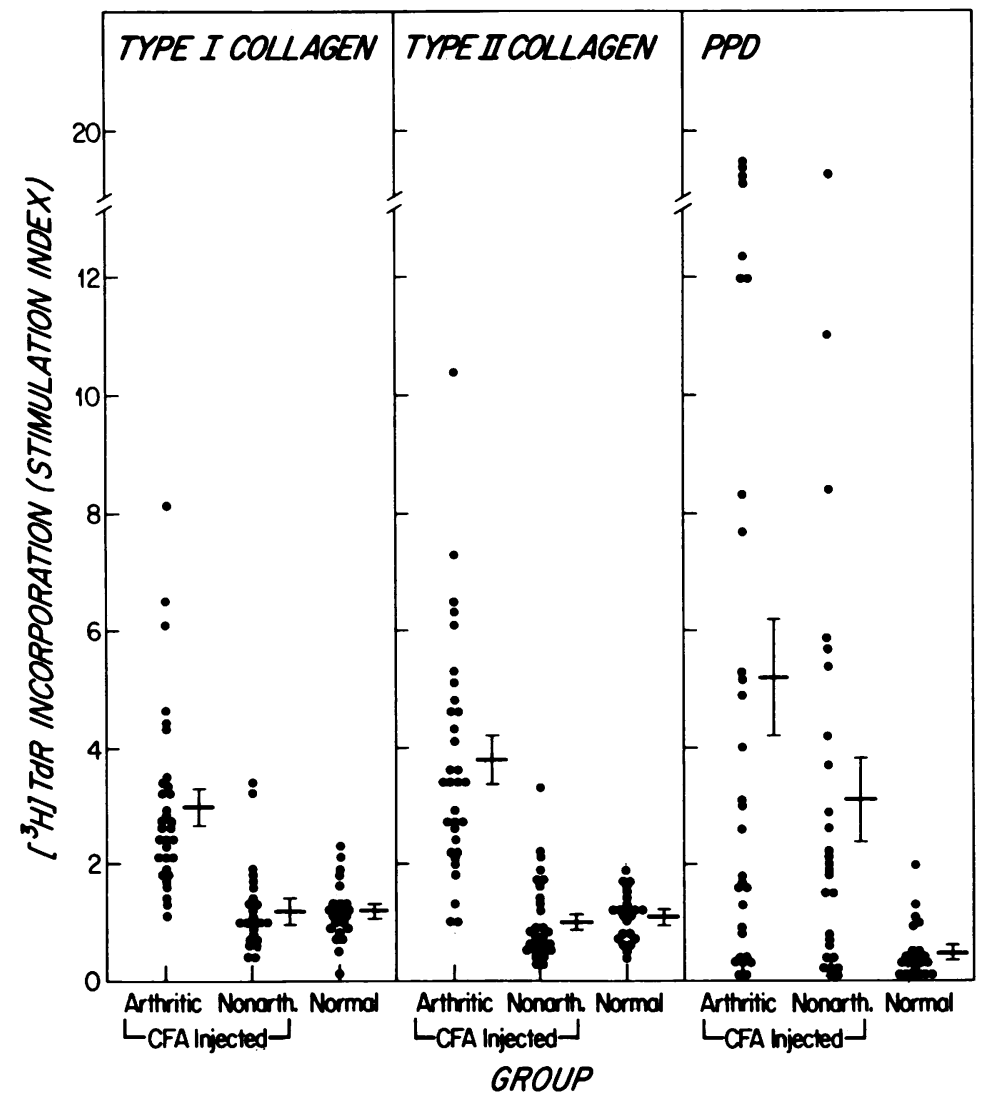

FIGURE 1 Comparison of collagen- and PPD-induced $\left[{ }^{3} \mathrm{H}\right] \mathrm{TdR}$ incorporation by cells from 32 arthritic vs. 28 nonarthritic rats injected $\sim 21$ d earlier with CFA H37Ra, as well as cells from 23 age-matched, uninjected rats. Insufficient cell yields precluded testing four nonarthritic rats with type I collagen and two arthritic and one nonarthritic rat with PPD. Mean background counts per minute $(727 \pm 82$ arthritic vs. $983 \pm 122$ nonarthritic vs. $1,631 \pm 269$ normal) and mitogen responses (for arthritic vs. nonarthritic vs. normal, mean SI to phytohemagglutinin $58 \pm 12$ vs. $45 \pm 8$ vs. $21 \pm 4$, mean SI to concanavalin A $165 \pm 36$ vs. $97 \pm 22$ vs. $42 \pm 10$ ) did not differ significantly for these groups. In all figures, horizontal lines represent group means \pm SEM. 


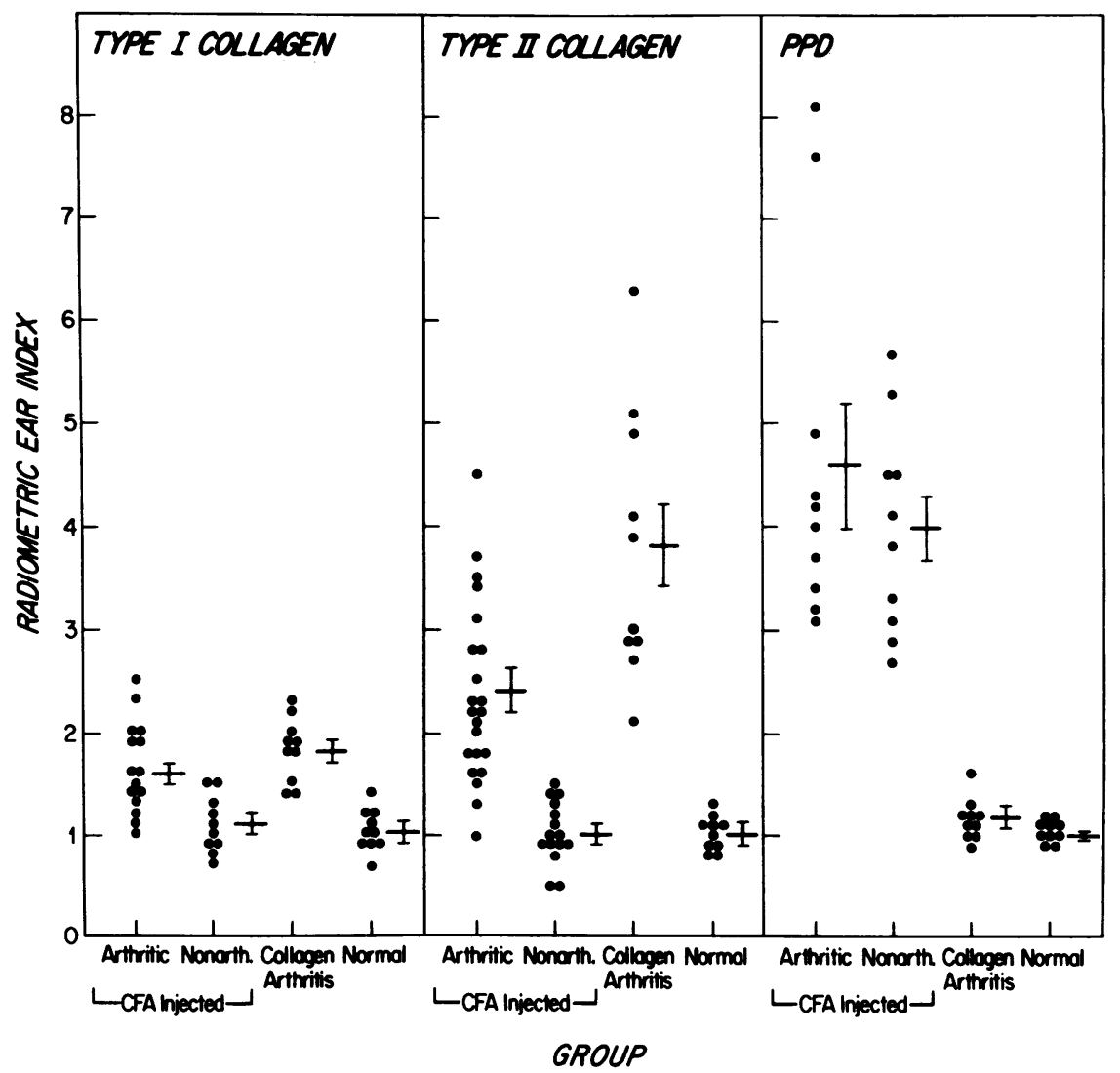

FIGURE 2 Intradermal delayed-type hypersensitivity responses to collagen and PPD measured in vivo by a radiometric ear assay in groups of $(a)$ arthritic vs. nonarthritic rats injected $\sim 21 \mathrm{~d}$ earlier with CFA H37Ra; (b) rats rendered arthritic by injection of rat type II collagen in incomplete Freund's adjuvant $\sim 21 \mathrm{~d}$ earlier; and $(c)$ age-matched uninjected rats. Mean counts per minute of $\left[{ }^{3} \mathrm{H}\right] \mathrm{TdR}$ in the nonantigen-challenged ears, used to derive the REI, were similar in the four groups (in the four respective groups, for type I collagen assays, $3,555 \pm 257 \mathrm{vs}$. $3,474 \pm 347 \mathrm{vs}$. $3,296 \pm 296$ vs. $2,892 \pm 276$; for type II collagen assays, $2,919 \pm 367$ vs. $2,812 \pm 302$ vs. $3,089 \pm 209$ vs. $3,754 \pm 530$; and for PPD assays, $3,218 \pm 278$ vs. $2,780 \pm 217$ vs. $3,875 \pm 498$ vs. $3,231 \pm 275$ ).

mean REI to type I collagen was $1.6 \pm 0.1$ vs. $1.1 \pm 0.1$, $P<0.002$, mean REI to type II collagen was $2.4 \pm 0.2$ vs. $1.0 \pm 0.1, P<0.0001$, and mean REI to PPD was $4.6 \pm 0.6$ vs. $4.0 \pm 0.3, P$ not significant). By this assay, the magnitude of the cellular response to type II collagen was significantly higher than that observed to type I collagen in rats with either adjuvant- $(P<0.006)$ or collagen-induced $(P<0.0002)$ arthritis. The absence of reactivity to PPD in the ear assays of rats with collagen-induced arthritis (Fig. 2) provides evidence against the possibility that a nonspecific enhanced cell migration to the skin accounted for our positive REI to collagen in arthritic rats, and indicates that collagen and PPD do not share cross-reacting cellular antigenic determinants.

Cellular sensitivity to denatured collagen in adjuvant arthritis. Cells from 14 arthritic rats, studied during the first 3 wk of adjuvant disease, exhibited less $\left[{ }^{3} \mathrm{H}\right] \mathrm{TdR}$ incorporation to the $\alpha$-chains of type I collagen than to the native molecules (mean SI, 3.4 \pm 0.5 to type I collagen vs. $0.9 \pm 0.2$ to $\alpha 1$ (I) chains, $P<0.001$, and $2.0 \pm 0.4$ to $\alpha 2$ chains, $P<0.03$ ). However, the $\left[{ }^{3} \mathrm{H}\right] \mathrm{TdR}$ incorporation responses to type II collagen vs. $\alpha 1$ (II) chains were not significantly different (mean SI, $2.9 \pm 0.5$ to type II collagen vs. 2.1 \pm 0.4 to $\alpha$ l (II) chains, $P$ not significant).

Serial studies of cellular autoimmunity to collagen in adjuvant arthritis. The relationship of cellular sensitivities to collagen and PPD with the course of adjuvant arthritis is depicted in Fig. 3. Cells obtained from 15 rats before the expected time of onset of adjuvant arthritis exhibited little $\left[{ }^{3} \mathrm{H}\right] \mathrm{TdR}$ incorporation to collagen or PPD. Histologic examination of the ankles of five of these rats showed no synovitis. In contrast, during the first $2 \mathrm{wk}$ of arthritis, the responses to collagen and PPD previously noted in Fig. 1 occurred. Reactivities were minimal in cells from the nine rats whose articular inflammation had subsided 


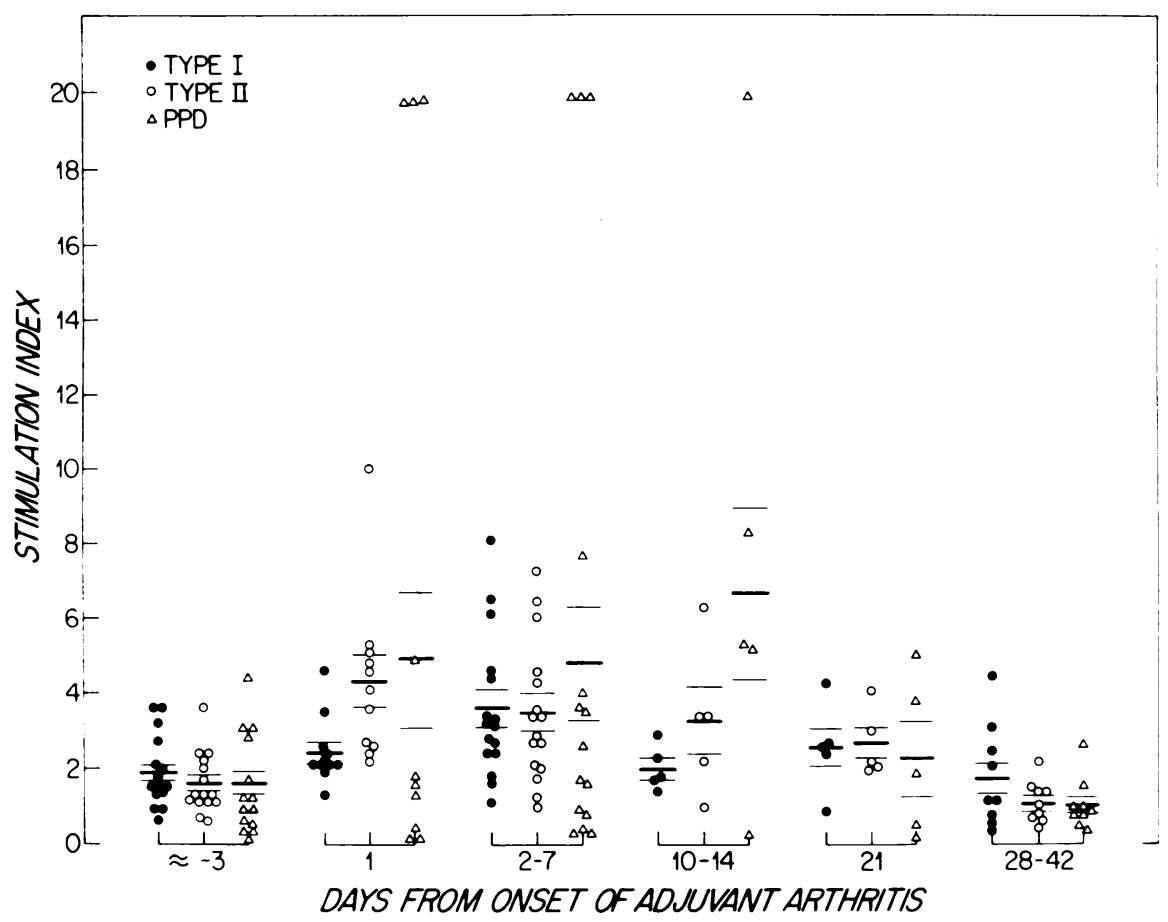

Figure 3 Comparison of collagen- and PPD-induced $\left[{ }^{3} \mathrm{H}\right] \mathrm{TdR}$ incorporation by cells from rats obtained at the indicated times during the course of adjuvant arthritis. The similar mean background of $635 \pm 101,650 \pm 125,662 \pm 102,1,094 \pm 291$, and $983 \pm 122 \mathrm{cpm}$ for the six groups, respectively, justify these comparisons. Insufficient cell yields precluded cultures with PPD on three occasions in these experiments. Day $\sim-3$ represents $10 \mathrm{~d}$ after injection of CFA H37Ra.

when studied by light microscopy 4-6 wk after the onset of arthritis. Although the responses to PPD correlated with the presence of active inflammation in these experiments, it should be recalled that cells from nonarthritic rats injected with CFA H37Ra were also sensitized to PPD (Fig. 1).

Autoantibodies to collagens in adjuvant arthritis. Although there were no hemagglutinating antibodies to collagen in sera from 20 adjuvant arthritic rats obtained during the first $3 \mathrm{~d}$ of disease, passive hemagglutination assays detected antibodies to homologous types I and II collagens and their $\alpha$-chains in the sera of $\sim 40 \%$ of the rats with adjuvant arthritis collected after the lst wk of disease (Fig. 4). No hemagglutinating antibodies to collagen were found in sera from 46 nonarthritic rats studied at varying times after injection of CFA H37Ra or in sera from 23 uninjected rats.

Specificities of autoantibodies to collagens. Hemagglutination techniques demonstrated that antibodies induced by immunization with native rat collagens are type specific. Antisera to rat type I collagen, obtained $21 \mathrm{~d}$ after immunization, agglutinated erythrocytes coated with type I collagen but not type II collagen (for 10 rats injected with type I collagen, mean $-\log _{2}$ antibody titer, $4.5 \pm 0.5$ to type $I$ vs. $0.5 \pm 0.2$ to type II collagen). Similarly, sera from 10 nonarthritic rats that had been injected with type II collagen $21 \mathrm{~d}$ earlier agglutinated type II collagen-coated erythrocytes, but not those coated with type I collagen (mean $-\log _{2}$ antibody titer, $6.0 \pm 0.2$ to type II collagen vs. 0 for type I collagen). In addition, antisera to these native collagens failed to react with the $\alpha$-chains of either collagen, indicating that the antibodies were directed toward helical antigenic determinants. The specificities of antibodies to denatured rat collagens could not be studied satisfactorily because our immunization regimen produced only minimal antibody titers to $\alpha$ chains.

Absence of sensitivity to collagen in turpentineinduced hindlimb inflammation. The reactivities to collagen in adjuvant arthritis could be explained by immunocompetent cells becoming exposed to collagen as a consequence of periarticular inflammation. Therefore, rats with a chemically induced hindlimb inflammation were examined to determine whether they acquired sensitivity to collagen. Weekly injections of turpentine into a hindpaw of 20 age-matched rats caused persistent swelling and erythema graded 4 by the arthritic index. Radiographic evaluation after 3-4 wk revealed severe joint destruction and an ex- 


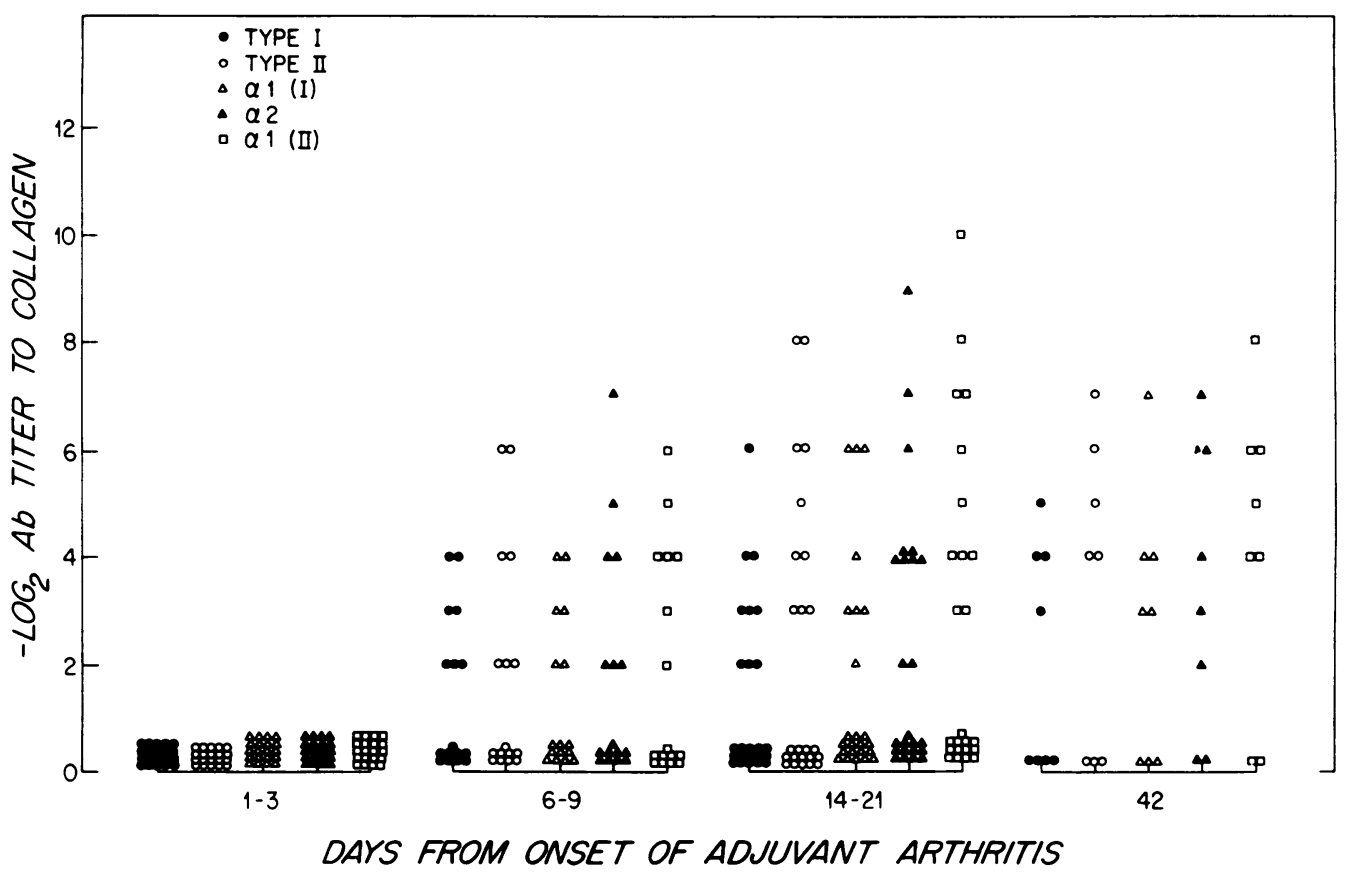

FIGURE 4 Antibody titers by passive hemagglutination to homologous native collagens and their $\alpha$-chains in sera of rats at varying times during the course of adjuvant arthritis. The titers were unaffected by absorbing adjuvant arthritic sera with varying concentrations of desiccated $M$. tuberculosis strain H37Ra, suggesting that immunogenic determinants present in the CFA H37Ra used to induce arthritis were not responsible for the production of these antibodies.

tensive periosteal reaction of the bones in the hindpaw. Histologically, there was an intense infiltration of the periarticular tissues by, predominantly, polymorphonuclear leukocytes. Flagrant damage to cartilage and bone was evident. At this time, cells from these rats did not exhibit enhanced $\left[{ }^{3} \mathrm{H}\right] \mathrm{TdR}$ incorporation to collagens, $\alpha$-chains, or PPD (mean background counts per minute $1,849 \pm 315$; mean SI to phytohemagglutinin, $11.6 \pm 2.7$; to concanavalin $\mathrm{A}, 17.6 \pm 9.4$; to type I collagen, $1.1 \pm 0.1$; to type II collagen, $1.3 \pm 0.2$; to $\alpha 1$ (I) chains, $0.8 \pm 0.1$; to $\alpha 2$ chains, $0.5 \pm 0.1$; to $\alpha 1$ (II) chains, $0.9 \pm 0.1$; and to PPD, $1.0 \pm 0.1)$. Their sera contained no hemagglutinating antibodies to native or denatured collagens.

Nonspecific inflammatory processes, such as those induced by carrageenan, may impair humoral $(44,45)$ or cellular (46-48) functions. Immunosuppression, possibly mediated by prostaglandins (49), could have prevented the development of collagen immunity in the turpentine model. We therefore injected 20 rats with type II collagen in incomplete Freund's adjuvant and simultaneously began the turpentine injections. After $4 \mathrm{wk}$, antibodies to type II collagen were present in the sera of 16 rats (mean titer, 6.4 \pm 0.6 ); cells from 9 rats responded to type II collagen (mean SI, 2.2 $\pm 0.4)$; and arthritis was evident in the uninjected hindlimb of 6.5 of 20 additional rats subjected to the turpentine protocol and injected with CFA H37Ra developed polyarthritis. These experiments show that rats with turpentine-induced hindlimb inflammation are capable of becoming sensitized to collagen and developing collagen or adjuvant arthritis. However, they provide only indirect evidence to suggest that, if it were appropriate, rats with turpentine-induced arthritis would be capable of acquiring sensitivity to collagen endogenously.

\section{DISCUSSION}

Adjuvant disease of rats is a systemic polyarthritis involving articular and dermal tissues $(6,11)$. While it has been presumed that a cellular response (17-19, $50-54)$ to one or more exogenous antigens derived from bacterial cell walls $(9,16,37,55-57)$ induces adjuvant arthritis, some investigators have considered that this disease comprises, at least partially, a response to one or more endogenous antigens $(20,21)$. Pearson (8) first suggested that adjuvant disease might represent an autoimmune reaction to collagen altered at the site of injection of CFA. Ryżewska (22) provided evidence for this hypothesis by reporting that intradermal injection of lymph node cells from rats with adjuvant arthritis into immunologically naive syngeneic recipients incited a species-specific delayed skin test reaction. 
He concluded that immunocompetent cells from the arthritic rats were reacting against antigens present in dermal connective tissue. The observation that lathyritic rats appeared to be less susceptible to adjuvant arthritis (23) prompted Steffen and Wick (24, $25)$ to investigate more directly whether collagen might function as an autoantigen in this model. Delayedtype skin reactions to denatured $(24,25)$ and native (25) rat skin (type I) collagen were elicited in some rats with adjuvant arthritis, although they failed to detect antibodies to skin collagen by passive hemagglutination (25).

Our study demonstrates that humoral and cellular autoimmune responses to homologous type I and type II collagens are present in rats with adjuvant-induced arthritis. Although antibodies to denatured collagens were frequently found in sera from arthritic rats, additional work is required to determine whether cellular responses to $\alpha$-chains are present in this model. Absorption of adjuvant arthritis sera with mycobacteria did not affect the antibody titers to collagen, and rats injected with type II collagen failed to display delayed hypersensitivity to PPD. Nonetheless we cannot, at present, further exclude the possibility that our findings are attributable to cross-reacting antigenic determinants shared by collagen and the mycobacterial preparation which we used to induce adjuvant arthritis.

It is possible that one collagen type functions as the principal autoantigen in adjuvant arthritis, with the reactivities to other collagen preparations being explained by cross-reacting antigenic determinants. Alternatively, specific humoral and cellular responses to native and denatured collagens could exist in this disease. Immunization with native types I and II collagens induces type-specific humoral (42) and cellular (27) responses in rats, but whether the responses to homologous collagens in adjuvant arthritis are also type specific is unknown.

Finally, our data do not distinguish whether autoimmunity to collagen plays a primary role in the pathogenesis of adjuvant arthritis or whether it represents a secondary response to connective tissue alterations in this inflammatory disease. Hemagglutinating antibodies to collagen appeared in the sera of arthritic rats only after arthritis had been present for several days. This temporal sequence could indicate that the humoral response to collagen in adjuvant arthritis required access of immunocompetent cells to collagen. We would caution that the absence of collagen reactivity in the turpentine model does not discredit this hypothesis, since the magnitude of inflammation induced by turpentine might have degraded collagen before it could function as an autoimmunogen.

Contrasting with the humoral response, cellular sensitivity to collagen was identified during the lst wk of morphologically evident adjuvant arthritis. This association would be consistent with cellular processes participating in the primary pathogenesis of adjuvant arthritis. However, we have recently shown that delayed hypersensitivity to homologous type II collagen can be induced in rats within $3 \mathrm{~d}$ by antigen-presentation techniques in the absence of adjuvant oil (58). This delineation suggests that macrophages may be capable of processing collagen exposed early in the course of adjuvant arthritis and generating the $T$ cell responses which we found during the initial stage of arthritis. Thus, the cellular response to collagen in adjuvant arthritis could also represent a secondary event unrelated to the actual pathogenesis of this disease.

Despite these reservations, our data support the hypothesis that injection of an adjuvant preparation into rats can trigger the expansion of lymphocyte clones which exhibit autoreactivity to collagen. These cells could contribute to the inflammation observed in adjuvant disease. Sensitized $\mathrm{T}$ cells, with helper functions, might also recruit B cell responses to collagen and explain the appearance of autoantibodies later in the course of adjuvant arthritis. Our passive transfer experiments (28) indicate that cells sensitized to type II collagen can induce arthritis in immunologically naive syngeneic rats. The present study provides evidence that cellular sensitivity to collagen may be related to the pathogenesis of adjuvant- as well as collagen-induced arthritis.

\section{ACKNOWLEDGMENTS}

We are indebted to Dr. John P. Caulfield for assistance in the histologic evaluation of synovia. We thank Donna Rowland and Roselynn Dynesius for excellent technical assistance.

This work was supported by National Institutes of Health grants AM-21490, AI-07685, AM-05076, AI-07167, AM-05588, RR-05669, and by a grant from the New England Peabody Home Foundation. Dr. Trentham is a Senior Investigator of the Arthritis Foundation.

\section{REFERENCES}

1. Stoerk, H. C., T. C. Bielinski, and T. Budzilovich. 1954 Chronic polyarthritis in rats injected with spleen in adjuvants. Am. J. Pathol. 30: 616. (Abstr.)

2. Pearson, C. M. 1956. Development of arthritis, periarthritis and periostitis in rats given adjuvants. Proc. Soc. Exp. Biol. Med. 91: 95-101.

3. Pearson, C. M. 1959. Development of arthritis in the rat following injection with adjuvant. In Mechanisms of Hypersensitivity. J. H. Shaffer, G. A. LoGrippo, and M. W. Chase, editors. Little, Brown \& Co., Boston. 647-671.

4. Pearson, C. M., and F. D. Wood. 1959. Studies of polyarthritis and other lesions induced in rats by injection of mycobacterial adjuvant. I. General clinical and pathological characteristics and some modifying factors. Arthritis Rheum. 2: 440-459.

5. Silverstein, E., and L. Sokoloff. 1960. Periarthritis produced in rats with Freund's adjuvants. Arthritis Rheum. 3: 485-495. 
6. Pearson, C. M., B. H. Waksman, and J. T. Sharp. 1961. Studies of arthritis and other lesions induced in rats by injection of mycobacterial adjuvants. V. Changes affecting the skin and mucous membranes. Comparison of the experimental process with human disease. J. Exp. Med. 113: 485-510.

7. Ward, J. R., and R. S. Jones. 1962. Studies on adjuvantinduced polyarthritis in rats. I. Adjuvant composition, route of injection, and removal of depot site. Arthritis Rheum. 5: 557-564.

8. Pearson, C. M. 1963. Experimental joint disease. Observations on adjuvant-induced arthritis. J. Chronic Dis. 16: 863-874.

9. Flax, M. H., and B. H. Waksman. 1963. Further immunologic studies of adjuvant disease in the rat. Int. Arch. Allergy Appl. Immunol. 23: 331-347.

10. Pearson, C. M., and F. D. Wood. 1963. Studies of arthritis and other lesions induced in rats by the injection of mycobacterial adjuvant. VII. Pathologic details of the arthritis and spondylitis. Am. J. Pathol. 42: 73-86.

11. Burstein, N. A., and B. H. Waksman. 1964. The pathogenesis of adjuvant disease in the rat. I. A histologic study of early lesions in the joints and skin. Yale J. Biol. Med. 37: 177-194.

12. Newbould, B. B. 1964 . Role of lymph nodes in adjuvantinduced arthritis in rats. Ann. Rheum. Dis. 23: 392-396.

13. Muirden, K. D., and G. Peace. 1969. Light and electron microscope studies in carragheenin, adjuvant, and tuberculin-induced arthritis. Ann. Rheum. Dis. 28: $392-401$.

14. Zahiri, H., J. Gagnon, R. Ayotte, and C. A. Laurin. 1969. Adjuvant experimental polyarthritis. Can. Med. Assoc. J. 101: 269-278.

15. Jasin, H. E., T. D. Cooke, E. R. Hurd, J. D. Smiley, and M. Ziff. 1973. Immunologic models used for the study of rheumatoid arthritis. Fed. Proc. 32: 147-152.

16. Hadler, N. M. 1976. A pathogenetic model for erosive synovitis: lessons from animal arthritides. Arthritis Rheum. 19: 256-266.

17. Waksman, B. H., and C. Wennersten. 1963. Passive transfer of adjuvant arthritis in rats with living lymphoid cells of sensitized donors. Int. Arch. Allergy Appl. Immunol. 23: 129-139.

18. Pearson, C. M., and F. D. Wood. 1964. Passive transfer of adjuvant arthritis by lymph node or spleen cells. J. Exp. Med. 120: 547-560.

19. Whitehouse, D. J., M. W. Whitehouse, and C. M. Pearson. 1969. Passive transfer of adjuvant-induced arthritis and allergic encephalomyelitis in rats using thoracic duct lymphocytes. Nature (Lond.). 224: 1322.

20. Chang, Y.-H., C. M. Pearson, and C. Abe. 1980. Adjuvant polyarthritis. IV. Induction by a synthetic adjuvant: immunologic, histopathologic, and other studies. Arthritis Rheum. 23: 62-71.

21. Berry, H., D. A. Willoughby, and J. P. Giroud. 1973. Evidence for an endogenous antigen in the adjuvant arthritic rat. J. Pathol. 111: 229-238.

22. Ryżewska, A. G. 1967. Skin test provoked by lymphoid cells deriving from rats with adjuvant-induced polyarthritis. Pathol. Eur. 2: 185-197.

23. Steffen, C., K. Formanek, and R. Timpl. 1965. Hemmung der Adjuvans-Arthritis durch Lathyrismus. Z. Immunitäts Allergieforsch. 128: 451-467.

24. Formanek, K., M. Rosak, and C. Steffen. 1964. Weitere Untersuchungen über die experimentelle AdjuvansArthritis der Ratte. Int. Arch. Allergy Appl. Immunol. 24: $39-59$

25. Steffen, C., and G. Wick. 1971. Delayed hypersensitivity reactions to collagen in rats with adjuvant-induced arthritis. Z. Immunitäts Allergieforsch. 141: 169-180.

26. Trentham, D. E., A. S. Townes, and A. H. Kang. 1977. Autoimmunity to type II collagen: an experimental model of arthritis. J. Exp. Med. 146: 857-868.

27. Trentham, D. E., A. S. Townes, A. H. Kang, and J. R David. 1978. Humoral and cellular sensitivity to collagen in type II collagen-induced arthritis in rats.J. Clin. Invest. 61: 89-96.

28. Trentham, D. E., R. A. Dynesius, and J. R. David. 1978 Passive transfer by cells of type II collagen-induced arthritis in rats. J. Clin. Invest. 62: 359-366.

29. Stuart, J. M., M. A. Cremer, A. H. Kang, and A. S. Townes. 1979. Collagen-induced arthritis in rats: evaluation of early immunologic events. Arthritis Rheum. 22: 13441351.

30. Rogers, M. P., D. E. Trentham, W. J. McCune, B. I. Ginsberg, P. Reich, and J. R. David. 1980. Abrogation of type II collagen-induced arthritis in rats by psychological stress. Trans. Assoc. Am. Physicians. 92: 218-228.

31. Morgan, K., R. B. Clague, M. J. Shaw, and P. J. L. Holt. 1980. Native type II collagen-induced arthritis in the rat. I. Incidence and humoral response to collagen. Ann. Rheum. Dis. 39: 285-290.

32. Stuart, J. M., M. A. Cremer, S. N. Dixit, A. H. Kang, and A. S. Townes. 1979. Collagen-induced arthritis in rats: comparison of vitreous and cartilage-derived collagens. Arthritis Rheum. 22: 347-352.

33. Trelstad, R. L., V. M. Catanese, and D. F. Rubin. 1976. Collagen fractionation: separation of native types I, II and III by differential precipitation. Anal. Biochem. 71: $114-118$.

34. Goodman, G. W., and B. M. Sultzer. 1979. Further studies on the activation of lymphocytes by endotoxin protein. J. Immunol. 112: 1329-1334.

35. Soria-Herrera, C., J. Morley, H. Inoue, and D. L. Gardner. 1971. Experimental turpentine arthritis: measurement of treated and untreated inflammatory response by the accumulation of ${ }^{125} \mathrm{I}$-albumin. J. Pathol. 104: 3. (Abstr.)

36. di Rosa, M., J. P. Giroud, and D. A. Willoughby. 1971. Studies of the mediators of the acute inflammatory response induced in rats in different sites by carrageenan and turpentine. J. Pathol. 104: 15-29.

37. Wood, F. D., C. M. Pearson, and A. Tanaka. 1969. Capacity of mycobacterial wax $D$ and its subfractions to induce adjuvant arthritis in rats. Int. Arch. Allergy Appl. Immunol. 35: 456-467.

38. Trentham, D. E., R. A. Dynesius, R. E. Rocklin, and J. R. David. 1978. Cellular sensitivity to collagen in rheumatoid arthritis. N. Engl. J. Med. 299: 327-332.

39. Sabolovic, D., M-C. Beugnot, F. Dumont, and M. Bujadoux. 1972. A new method to measure the specific cellular component of a delayed hypersensitivity response in the ear of the mouse. Eur. J. Immunol. 2: 604-606.

40. Vadas, M. A., J. F. A. P. Miller, J. Gamble, and A. Whitelaw. 1975. A radioisotopic method to measure delayed type hypersensitivity in the mouse. I. Studies in sensitized and normal mice. Int. Arch. Allergy Appl. Immunol. 49: 670-692.

41. Kostiala, A. A. I. 1977. Radiometric ear index test as a measure of delayed-type hypersensitivity in the rat. Immunology. 33: 561-571.

42. Hahn, E., R. Timpl, and E. J. Miller. 1974. The production of specific antibodies to native collagens with the chain compositions, $[\alpha 1(\mathrm{I})]_{3},[\alpha 1(\mathrm{II})]_{3}$, and $[\alpha 1(\mathrm{I})]_{2} \alpha 2 . J$. Immunol. 13: 421-423.

43. Baumgartner, W. A., F. W. J. Beck, A. Lorber, C. M. Pearson, and M. W. Whitehouse. 1974. Adjuvant disease 
in rats: biochemical criteria for distinguishing several phases of inflammation and arthritis. Proc. Soc. Exp. Biol. Med. 145: 625-630.

44. Ascheim, L., and S. Raffel. 1972. The immunodepressant effect of carrageenin. J. Reticuloendothel. Soc. 11: 253-262.

45. Thomson, A. W., A. R. Wilson, W. J. Cruickshank, and C. H. W. Horne. 1976. Evaluation of carrageenan as an immunosuppressive agent and mediator of intravascular coagulation. Biomedicine (Paris). 24: 102-106.

46. Schwartz, H. J., and S. Leskowitz. 1969. The effect of carrageenan on delayed hypersensitivity reactions. $J$. Immunol. 103: 87-91.

47. Bice, D., H. J. Schwartz, W. W. Lake, and J. Salvaggio. 1971. The effect of carrageenan on the establishment of delayed hypersensitivity. Int. Arch. Allergy Appl. Immunol. 41: 628-636.

48. Schwartz, H. J., and P. J. Catanzaro. 1973. The differential suppression of antigen, lymphokine and mitogeninduced delayed hypersensitivity-type skin reactions by carrageenan. Int. Arch. Allergy Appl. Immunol. 44: 409-421.

49. Rumjanek, V. M., S. R. Watson, and V. S. Šljivić. 1977. A re-evaluation of the role of the macrophages in carrageenan-induced immunosuppression. Immunology. 33: 423-432.

50. Currey, H. L. F., and M. Ziff. 1968. Suppression of adjuvant disease in the rat by heterologous antilymphocyte globulin. J. Exp. Med. 127: 185-203.

51. Kayashima, K., T. Koga, and K. Onoue. 1978. Role of T lymphocytes in adjuvant arthritis. II. Different sub- populations of lymphocytes functioning in the development of the disease. J. Immunol. 120: 1127-1131.

52. Eugui, E. M., and R. H. Houssay. 1975. Passive transfer of unresponsiveness by lymph node cells: studies on adjuvant disease. Immunology. 28: 703-710.

53. Kayashima, K., T. Koga, and K. Onoue. 1976. Role of T lymphocytes in adjuvant arthritis. I. Evidence for the regulatory function of thymus-derived cells in the induction of the disease. J. Immunol. 117: 1878-1882.

54. Parham, M. J., G-A. P. Schoester, T. H. van der Kwast, and $R$. Brenner. 1979. Alterations in granulation tissue growth induced in vivo by lymphocytes from adjuvantdiseased rats. Int. Arch. Allergy Appl. Immunol. 58: 227-231.

55. Waksman, B. H., C. M. Pearson, and J. T. Sharp. 1960. Studies of arthritis and other lesions induced in rats by injection of mycobacterial adjuvant. II. Evidence that the disease is a disseminated immunological response to exogenous antigen. J. Immunol. 85: 403-417.

56. Stewart-Tull, D. E. S., T. Shimono, S. Kotani, M. Kato, Y. Ogawa, Y. Yamamura, T. Koga, and C. M. Pearson. 1975. The adjuvant activity of a non-toxic, water-soluble glycopeptide present in large quantities in the culture filtrate of Mycobacteria tuberculosis strain DT. Immunology. 29: 1-15.

57. Paronetto, F. 1970. Adjuvant arthritis induced by Corynebacterium rubrum. Proc. Soc. Exp. Biol. Med. 133: 296-298.

58. Schoen, R., L. Perry, D. Trentham, M. Greene, B. Benacerraf, and J. David. 1980. Reactivity to self induced by collagen-coupled spleen cells. Clin. Res. 28: 552. (Abstr.) 